NBER WORKING PAPER SERIES

\author{
EMPLOYMENT-BASED HEALTH \\ INSURANCE AND JOB MOBILITY: \\ IS THERE EVIDENCE OF JOB-LOCK?
}

Brigitte C. Madrian

Working Paper No. 4476

\author{
NATIONAL BUREAU OF ECONOMIC RESEARCH \\ 1050 Massachusetts Avenue \\ Cambridge, MA 02138 \\ September 1993
}

I an grateful for many helpful discussions with Janet Currie, David Cutler, Peter Diamond, Henry Farber, Jerry Hausman and James Poterba and acknowledge financial support from the National Science Foundation, the Lynde and Harry Bradley Foundation, and the National Institute of Aging. This paper is part of NBER's research program in Public Economics. Any opinions expressed are those of the author and not those of the National Bureau of Economic Research. 
NBER Working Paper \#4476

September 1993

\title{
EMPLOYMENT-BASED HEALTH \\ INSURANCE AND JOB MOBILITY: \\ IS THERE EVIDENCE OF JOB-LOCK?
}

\begin{abstract}
This paper assesses the impact of employer-provided health insurance on job mobility by exploring the extent to which workers are "locked" into their jobs because preexisting conditions exclusions make it expensive for individuals with medical problems to relinquish their current health insurance. I estimate the degree of job-lock by comparing the difference in the turnover rates of those with high and low medical expenses for those with and without employer-provided health insurance. Using data from the 1987 National Medical Expenditure Survey, 1 estimate that job-lock reduces the voluntary turnover rate of those with employer-provided health insurance by 25 percent, from 16 percent to 12 percent per year.
\end{abstract}

\author{
Brigitte C. Madrian \\ Department of Economics \\ Littauer Center \\ Harvard University \\ Cambridge, MA 02138 \\ and NBER
}


The majority of privately insured Americans obtain their health insurance through their own or a family member's employment. The rationale for employers to provide health insurance is straightforward. By pooling the risks of individuals, employers can reduce adverse selection and lower administrative expenses; in addition, they benefit from tax laws allowing businesses to deduct their health insurance costs. These advantages of employer provision must be weighed, however, against the distortions they may generate in individual labor market decisions. In particular, health insurance may distort job mobility if employees decide to keep jobs they would rather leave for fear of losing coverage for preexisting conditions, ' a possibility that has been termed "job-lock." This paper attempts to quantify the effect of employer-provided health insurance on the labor market mobility of individuals.

The link between employer-provided health insurance and labor market mobility is a potentially important factor in evaluating several competing proposals to reform the U. S. health care system. To the extent that these proposals affect the link between employment and health insurance, they could have substantially different effects on the degree of

${ }^{1}$ A preexisting condition is generally defined as any medical problem which has been treated or diagnosed within the past six months to two years. In some cases it may be more broadly defined as any medical problem for which an individual has ever received care or for which a prudent person would have sought care even if no physician was actually consulted. 
job-lock, yet there is little empirical evidence on the relationship between health insurance and job mobility. Job-lock may also be an important concern if there is a match-specific component of productivity that makes workers more productive in some jobs than in others [Jovanovic, 1979]. The productivity of the economy as a whole will suffer if individuals who would like to move to more productive jobs are constrained to keep their current positions simply to maintain their health insurance.

To test for the presence of job-lock, I examine the relationship between turnover, health insurance status, and expected medical expenses. If job-lock is important, individuals with employer-provided health insurance should be less likely to leave their jobs the higher are their expected medical expenses. However, job-lock should only affect those who actually have group employment health insurance. I estimate the extent of job-lock using a difference-in-difference approach: the mobility difference between those with high and low expected medical expenses should be greater for those with employer-provided health insurance than for those whose jobs do not include insurance. This test allows me to distinguish the effect of employer-provided health insurance on mobility from other factors related to mobility. I consider three different "experimental" groups: married men who have an alternative source of coverage in addition to their own employer-provided health insurance, heads of large families who are more likely to have high expected medical expenses simply because of the size of their family, and married men whose wives are pregnant. Using data from the 1987 National Medical Expenditure Survey, I estimate that job-lock reduces the voluntary turnover rate of those with employer-provided health insurance by 25 percent. 
The paper is organized as follows. Section I provides some background on the link between health insurance and worker mobility. Section II details the methodology I use to identify job-lock; this is followed in Section III by a description of the data. The empirical results are presented in Section IV, and the paper concludes in Section V.

\section{Background and Motivation}

There is abundant anecdotal evidence in support of insurancerelated job-lock. In a recent $\mathrm{CBS} / \mathrm{New}$ York Times poll, 30 percent of respondents answered "Yes" to the question "Have you or anyone else in your household ever decided to stay in a job you wanted to leave mainly because you didn't want to lose health coverage?" [New York Times, September 6, 1991]. That so many individuals feel constrained by the need for health insurance is telling evidence on the importance of health insurance in job decisions. If employees knew that all of their illnesses would receive identical coverage regardless of whether they worked, where they worked, or how long they had been on the job, health insurance would not be a deterrent to worker mobility.

The problem, however, is that employees do not necessarily receive identical coverage when they change jobs because 57 percent of employers exclude preexisting conditions, typically for six months to two years, in their health plans [Cotton, 1991]. Although small firms are more likely to impose these exclusions (64 percent of firms with under 500 employees), 45 percent of firms with more than 10,000 employees had them as well. In addition, half of full-time workers face length-of-service requirements before being eligible for any insurance [Bureau of Labor Statistics, 1989]. There is also a growing trend toward medical 
underwriting, especially in small firms, in order to exclude serious ailments from coverage entirely. ${ }^{2}$

In its 1985 COBRA (Consolidated Omnibus Budget Reconciliation Act) legislation, Congress attempted to ease the burden of possibly losing covering by mandating that employers provide terminating employees with the option to continue their coverage for up to 18 months. ${ }^{3}$ However, the cost of COBRA to the employee (102 percent of the employer's premium) may be prohibitively high at a time when individuals can least afford it (Spencer Associates [1991] reports that the average monthly COBRA health insurance premium for family coverage was $\$ 300$ in 1990).

Job-lock may be further exacerbated by the importance of experience rating in setting a firm's health insurance premiums. For small employers, one major illness may significantly increase the firm's premiums for several years. To avoid this possibility, employers may discriminate by refusing to hire employees with health problems, or when such events occur, they may cancel their policies altogether. Although the Americans with Disabilities Act prohibits screening for health in hiring, it places no constraints insurers; a firm's insurance company may exclude an individual from coverage or drop the plan entirely if the firm hires an employee with sufficiently high medical costs. Fear of this event may

${ }^{2}$ Medical underwriting occurs when certain medical conditions are excluded on an individual basis for the life of the insurance policy. For example, if an individual has had cancer, the insurance company may underwrite the policy to exclude any further expenses related to cancer for that individual. Such underwriting is often a precondition to providing insurance in small firms.

3 Gruber and Madrian [1993] examine the extent to which the availability of continuation coverage mitigates the effects of job-lock. 
discourage individuals from moving to small firms or leaving a job where they know their insurance premiums will not fluctuate.

\section{Identifying Job-Lock}

To study the phenomenon of job-lock, one would ideally like information on individual and family health status, worker mobility, and the health insurance plans of both the firm for which an individual works and to which an individual could move. Unfortunately, information on health status and health insurance is not widely available in labor force surveys, information on worker mobility is not typically available in health surveys, and information on insurance plans of companies for which an individual could have worked is nonexistent. An alternative approach is to identify two groups of workers who are similar in all respects except for either their health status or their insurance status and then compare the mobility of these two groups. I consider three factors associated with health and insurance status which should affect the cost of relinquishing health insurance upon changing jobs and then examine the mobility rates of individuals affected by these cost factors for evidence of job-lock.

\section{A. Cost Factor 1: Having Other Health Insurance}

The first division is between those who have an alternative source of coverage as well as their own employer-provided health insurance and those who do not. Table I lists the fraction of married men who report coverage from various sources of insurance. Although employers are the predominant provider of health insurance, more than one-third of the men with employer-provided insurance have an alternative source of insurance not attached to their own employment. For most men, this secondary 
source is the employer-provided insurance received by their working wives; other sources include Medicaid, CHAMPUS, and individual nongroup policies.

A useful framework for considering the effect of job-lock is provided by the following matrix of mobility rates by employer-provided and other health insurance status, where $M$ represents the probability of changing jobs in each cell.

\begin{tabular}{lll}
\hline \hline & \multicolumn{2}{c}{$\begin{array}{c}\text { Employer-Provided } \\
\text { Health Insurance }\end{array}$} \\
\cline { 2 - 3 } & No & Yes \\
\hline No Other HI & $\mathbf{M}_{00}$ & $\mathbf{M}_{01}$ \\
Other HI & $\mathbf{M}_{10}$ & $\mathbf{M}_{11}$ \\
\hline \hline
\end{tabular}

Because job-lock is caused by the potential loss of health insurance coverage associated with changing jobs, we would not expect those with coverage through both their own employment and an outside source to face job-lock. A simple test for the magnitude of job-lock, therefore, is whether those with employer-provided health insurance and other coverage are more likely to turnover than those without alternative coverage, or $M_{11}-M_{01}>0$. This will provide a consistent estimate of job-lock as long as individuals with other health insurance are not more likely to change jobs for reasons unrelated to job-lock. There may, however, be grounds to believe that mobility will be greater for those with other health insurance for reasons other than job-lock. For example, a man whose wife has employer-provided health insurance also has a secondary source of income, something which might increase mobility as well. A second test 
for job-lock, therefore, is whether having other health insurance increases mobility more for those who have employment-based health insurance than for those who do not, or

$$
\left(M_{11}-M_{01}\right)-\left(M_{10}-M_{00}\right)>0 .
$$

This difference-in-difference estimate for the effect of job-lock is consistent under the assumption that the independent effect of other health insurance on mobility is the same for those with employer-provided health insurance as it is for those without employer-provided health insurance.

It is important to note that looking at the effect of health insurance on mobility $\left(\mathbf{M}_{00}-\mathbf{M}_{01}\right.$ or $\left.\mathbf{M}_{10}-\mathbf{M}_{11}\right)$ cannot be construed as a test for joblock, as health insurance could be correlated with other unobserved job attributes that also tend to reduce mobility. For example, jobs which include health insurance benefits may also be "better" along other dimensions, such as providing a pension or paid vacation days. The two difference estimators proposed avoid this objection.

\section{B. Cost Factor 2: Expected Medical Expenses and Family Size}

Because job-lock should be more severe for those who most need health insurance, a second "experiment" for job-lock compares mobility rates for those with and without high expected medical expenses. Although the data which I use do not include good measures of health status, one variable that should be correlated with expected medical expenses is family size. Larger families will have higher absolute medical expenses because they will make more routine visits to the doctor; it is also more likely that there will be a considerable medical expense in a 
larger family simply because there are more people who might have something go wrong.

If the expected medical expenses associated with family size decrease mobility, then among those with employer-provided health insurance, individuals with small families should be more likely to change jobs than individuals with large families. To the extent that job mobility and geographic mobility are related, we might expect lower job turnover among those with large families simply because the costs associated with moving geographically are greater. If family size exerts this type of independent effect on mobility, an additional test for job-lock which separates out this confounding effect is whether the differential mobility rate between small and large families is greater for those who have employer-provided health insurance than for those who do not.

\section{Cost Factor 3: Expected Medical Expenses and Pregnancy}

Another easily identifiable group with large anticipated medical expenses is those who are expecting the birth of a child. The Health Insurance Association of America reported in 1989 that average costs for a normal pregnancy and delivery were $\$ 4,334$ while average cesarean costs were $\$ 7,186$. While looking at the mobility of pregnant women may be problematic since many women choose to leave the labor force (at least temporarily) when they have a baby, these objections should be less severe when considering the mobility decisions of their husbands.

A third test for job-lock, therefore, is whether among men employer-provided health insurance, those whose wives are pregnant are less likely to change jobs than those whose wives are not pregnant. As with family size and other health insurance, looking purely at the effect of 
pregnancy among those with health insurance may not be sufficient to identify job-lock if there are reasons why individuals who are expecting a baby may have different mobility patterns than everyone else. ${ }^{4}$ Once again, however, we can look at whether having a pregnant wife reduces mobility more for men who have employer-provided health insurance than for men who do not.

\section{Empirical implementation}

Empirically, the effect of job-lock is estimated from the following type of probit equation:

$$
\begin{aligned}
& \text { Probability of }=\Phi\left(\beta_{0}+\beta_{1} \bullet \begin{array}{c}
\text { Health } \\
\text { Insurance }
\end{array}+\beta_{2} \bullet \begin{array}{c}
\text { Cost } \\
\text { Factor }
\end{array}\right. \\
& \text { Changing Jobs } \\
& \left.+\beta_{3} \cdot \underset{\text { Insurance }}{\text { Health }} \underset{\text { Factor }}{\text { Cost }}+\mathbf{z}^{\prime} \gamma\right) \\
& =\Phi\left(A_{i}\right)
\end{aligned}
$$

where the vector $\mathbf{z}$ is a vector of observable demographic characteristics (such as education) and the cost factors are those just described: having other non-employment-related health insurance, family size, and pregnancy. This type of probit (or logit) specification has been used

${ }^{4}$ For example, the onset of fatherhood may have a "settling" effect on an individual's lifestyle, or individuals may not want to cope with the stress of changing jobs and having a baby at the same time. 
extensively in the existing empirical literature examining job turnover. ${ }^{5}$

The relationship between the estimated $\beta$ s and the tests of job-lock is straightforward. Using the other health insurance experiment in the previously shown mobility matrix, the estimated constant term, $\beta_{0}$, corresponds to the mobility rate (conditional on $z$ ) for individuals who have no health insurance coverage, either by themselves or through someone else. $\beta_{1}$ and $\beta_{2}$ give the marginal impact on mobility associated with holding employer-provided health insurance $\left(\beta_{1}\right)$ and having other health insurance $\left(\beta_{2}\right)$; and $\beta_{3}$ gives the extra impact on mobility generated by having both sources of health insurance coverage. The tests of joblock, therefore, are tests about the sign and magnitude of the estimated $\beta \mathrm{s}$.

The actual estimation is complicated by the fact that in my data, I observe individuals at two points in time separated by intervals of between 7 and 15 months. ${ }^{6}$ The only information I have on turnover is whether the individual is on the same job at the end of the interval as at

5 These include several studies which examine the impact of fringe benefits, particularly pensions, on turnover [Mitchell, 1982 and 1983; McCormick and Hughes, 1984; Bartel, 1982; Bartel and Borjas, 1977; Schiller and Weiss, 1979]. Generally these studies conclude that pensions and other fringe benefits are associated with lower mobility rates, although it is not clear whether this is because pensions are typically nonportable or because pensions are correlated with other favorable aspects of a job [Gustman and Steinmeier, 1987 and 1990].

See Mortensen [1986] and Mitchell [1983] for a model of job turnover that explicitly derives this type of estimating equation in a utility maximization framework.

${ }^{6}$ This is a problem of other panel data sets as well. In the PSID, time between interviews also varies from 7 to 15 months, while in the NLSY it varies from 9 to 20 months. 
the beginning. Thus, I know whether or not an individual changed jobs at least once.

If $P_{i t}$ denotes the probability that individual $i$ changes jobs in any given month $t$, then the probability that individual $i$ does not change jobs over an interval of $m$ months is

$$
\left(\begin{array}{c}
\text { Probability of } \\
\text { Not Changing Jobs }
\end{array}\right)_{i}=\prod_{i=1}^{m}\left(1-P_{i t}\right)
$$

Similarly, the probability of at least one job change over the same interval is

$$
\left(\begin{array}{l}
\text { Probability of } \\
\text { Changing Jobs }
\end{array}\right)_{i}=1-\prod_{i=1}^{m}\left(1-P_{i k}\right)
$$

If the probability of job change in any month is independent of that in any other month, these two probabilities reduce to

$$
\begin{aligned}
\left(\begin{array}{c}
\text { Probability of } \\
\text { Not } \text { Changing Jobs }
\end{array}\right)_{i} & =\left(1-P_{i}\right)^{m}=\left(1-\Phi\left(A_{i}\right)\right)^{m} \\
\left(\begin{array}{l}
\text { Probability of } \\
\text { Changing Jobs }
\end{array}\right)_{i} & =1-\left(1-P_{i}\right)^{m}=1-\left(1-\Phi\left(A_{i}\right)\right)^{m} .
\end{aligned}
$$

If, however, individuals have different underlying propensities to change jobs (i.e., there are "movers" and "stayers"), these probabilities may not be independent. To explicitly account for this, I also include an individual-specific random effect, $\theta_{i}$, in the estimation. I assume that $\theta_{i}$ is distributed normally with mean 0 and variance $\sigma_{\theta}^{2}$, a parameter which will also be estimated. The respective probabilities of changing jobs and not changing jobs are now given as 
(4)

$$
\begin{aligned}
\left(\begin{array}{c}
\text { Probability of } \\
\text { Not Changing Jobs }
\end{array}\right)_{i} & =\left(1-P_{i}\right)^{m}=\left(1-\Phi\left(A_{i}+\theta_{i}\right)\right)^{m} \\
\left(\begin{array}{l}
\text { Probability of } \\
\text { Changing Jobs }
\end{array}\right)_{i} & =1-\left(1-P_{i}\right)^{m}=1-\left(1-\Phi\left(A_{i}+\theta_{i}\right)\right)^{m} .
\end{aligned}
$$

For those who change jobs, their individual contribution to the likelihood function is

$$
L_{i}=\int_{-\infty}^{\infty}\left[1-\left(1-\Phi\left(A_{i}+\theta_{i}\right)\right)^{m}\right] \cdot f(\theta) d \theta,
$$

while for those who do not change jobs,

$$
L_{i}=\int_{-\infty}^{\infty}\left(1-\Phi\left(A_{i}+\theta_{i}\right)\right)^{m} \cdot f(\theta) d \theta
$$

\section{Data: 1987 National Medical Expenditure Survey}

The data I use come from the 1987 National Medical Expenditure Survey (NMES) conducted by the Agency for Health Care Policy and Research (AHCPR). This survey of approximately 14,000 households $(38,446$ individuals) collected detailed information about health status, health insurance, and medical care utilization in 1987 through a series of four interviews. Additionally, several questions relating to employment were asked during each of the four interview rounds. I restrict the sample to married men ages 20-55 who were full-year eligible respondents, employed but not self-employed at the first interview, and married to the 
same individual at the first and fourth interviews. ${ }^{7}$. The final sample consisted of 2978 individuals.

The dependent variable used in all specifications equals 1 if the individual changed jobs voluntarily. The data include an indicator variable for whether an individual held a different job at the last interview than in previous interviews. I code these individuals as well as those who are not employed at the final interview as job changers (everyone in the sample is employed at the first interview). There are also three questions in each round regarding whether an individual is currently laid-off or spent any time during the previous round on layoff. If the individual changed jobs and answered yes to any of these layoff questions after the first round, I assume that the individual changed jobs involuntarily. Therefore, voluntary job-changers are coded as those who either changed jobs between the first and the fourth interview or who became unemployed and who did not spend any time on layoff after the first interview. ${ }^{8}$ In my sample, 16 percent of individuals changed jobs and 12 percent changed voluntarily. These numbers are not out of line with one year mobility rates reported elsewhere. Although the empirical results reported are confined to an examination of voluntary mobility, it should be noted that

${ }^{7}$ Military personnel are not included in the sample because they are considered "out-of-scope" while they are in the military.

${ }^{8}$ This measure may slightly overstate the degree of voluntary mobility if there are individuals who were laid-off but did not spend any time unemployed (since questions regarding layoff were only asked of those who were or had been unemployed). Data from the January 1987 Current Population Survey suggest that $23 \%$ of those who lost the job they held a year previously found a new job within 2 weeks. If none of these individuals experienced any unemployment, this would lower fraction of those who left their jobs voluntarily by $1 \%$ at most (from $12 \%$ to $11 \%$ ). 
the results are very similar when the dependent variable equals 1 for any job change, voluntary or involuntary.

Table II presents descriptive statistics for variables used in the analysis. Some details of their construction follow. In addition to other demographic variables such as race, union status and education, experience is included as an independent variable in all specifications. Because the 1987 NMES asks how many years an individual spent not working after age 21 for several reasons including school, caring for children, and poor health, I adjust the traditionally used measure of labor market experience, age-education- 6 , to account for any additional time spent out of the labor force. ${ }^{9}$ The wage variable used was constructed by the Agency for Health Care Policy Research (AHCPR) using information on wage and salary payments, the time period covered by the payment (i.e. hourly, weekly, monthly), and the usual number of hours and days worked. The family and individual income variables were also constructed by AHCPR.

All three experiments used to test for job-lock include a dummy variable for whether or not an individual actually holds an employmentrelated health insurance policy. 72.5 percent of my sample are coded as holding such health insurance. The first experiment, which uses other health insurance to identify job-lock, also includes a dummy variable equal to 1 if an individual is covered by another source of health insurance (union, CHAMPUS, nongroup, and spousal health insurance).

The second experiment uses family size to identify job-lock. Family size should only matter, however, if an individual's health

${ }^{9}$ Because most men do not typically spend much time out of the labor force for reasons other than education, this measure of experience and the traditional measure are not that different. 
insurance policy actually covers others in the family. Unfortunately, the 1987 NMES does not give information about the source of coverage for individuals who are covered but do not actually hold a policy. I have therefore constructed two measures of whether a husband's employerprovided health insurance covers others.

In both cases I have assumed that if the husband is the only family member with group employment health insurance and his spouse or children are covered by this type of insurance, then the husband's policy covers everyone. In my conservative estimates, I have further assumed that if both parents hold employer-provided health insurance, the husband only covers himself. This will obviously understate the extent to which an individual covers others. Using this criterion, 51.3 percent of the sample (and 68 percent of those who have employer-provided health insurance) have health insurance that covers others.

In the liberal estimates I have assumed that if the children and wife are covered and the husband holds a group employment policy, then this policy covers everyone, regardless of whether or not the wife also holds group employment insurance. With this definition, 62.8 percent of the sample (83.4 percent of those with employer-provided insurance) have insurance that covers others. This estimate will overstate the coverage of others (especially to the extent that individuals do not have the option of family coverage), but is likely closer to the truth than the conservative estimate. A comparison with similar data from the May 1988 Current Population Survey suggests that this bias is likely to be small. ${ }^{10}$ Even if

${ }^{10}$ In a similar sample of married men from the May 1988 CPS, $64.9 \%$ have employer-provided health insurance which covers others and this is $79.1 \%$ of those with such insurance. These numbers are very close to the 
individuals do not actually elect family coverage, they may usually add other family members to their policy outside the open-enrollment period if other family members have lost their insurance due to a change in the spouse's employment. ${ }^{11}$

In determining coverage from a wife's health insurance policy. I have assumed that if the wife holds employer-provided health insurance, her husband is also covered. ${ }^{12}$ This corresponds to the liberal measure for covering children just described. In principle I could also make a conservative measure of coverage by a wife's policy analogous to that for covering children, but it would not be possible to identify job-lock in the estimation. With a conservative measure, only those who do not have employer-provided health insurance could be coded as having coverage through a wife's policy. An interaction between having your own employer-provided health insurance and being covered by a wife's health insurance would therefore equal zero for everyone.

The third experiment identifies job-lock using pregnancy as a preexisting condition. Because I only observe births and not pregnancy,

numbers I have calculated with the liberal estimate of covering others.

"Neither measure, however, accounts for the possibility that an individual could have coverage through his or her employment but does not even elect individual coverage because he or she already has coverage elsewhere.

${ }^{12}$ Using this definition, $33.5 \%$ of my sample are coded as having health insurance through their spouse's employment. In the May 1988 CPS, $33.9 \%$ of married men have wives with employer-provided health insurance. Of these women, $80 \%$ have insurance which covers others in the family, a figure roughly similar to that for men in both the NMES and the CPS. 
I construct two measures of pregnancy. The first is simply a dummy variable for whether or not a baby was born between the first interview and December 31, 1987. The second is the fraction of time between the first interview and the end of the year during which an individual's wife was pregnant. ${ }^{13}$ Using this second measure gives a stronger test of joblock. Among those who have employer-provided health insurance, individuals whose children are born shortly after the first interview should be more likely to change jobs than individuals whose children are born at the end of the year. This is because after the baby is born, the deterrent to mobility which kept the individual from changing jobs is gone (assuming the baby is healthy). Unfortunately, since I do not have information about births after the end of 1987 , neither measure accounts for pregnancies that were ongoing at the end of the year. This lack of information will bias the estimate of pregnancy-related job-lock downward because the mobility of the control group will be contaminated by some individuals who are also actually affected by job-lock.

\section{Empirical Results}

Tables 3-5 present the empirical results from estimating the probability of changing jobs as a function of the cost factors outlined previously. All specifications include the demographic variables described previously as well as 5 industry and 4 occupation dummies (although these

${ }^{13}$ Although birthdays are not reported in the NMES, I can identify the date of birth for children born after January 1, 1987 and before December 31,1987 because they are only eligible for the survey once they are born and I know the number of days for which an individual was eligible for inclusion. 
coefficients are not reported). Except where noted, all specifications include the full sample of 2,978 men.

The first column in Table III lists the coefficients from a simple probit equation for turnover which does not include any of the variables used to identify job-lock. Wages, union status, and experience are all negatively associated with turnover, while the effects of education and race are insignificant. As expected, the time between interviews increases the likelihood of turnover.

The second column of Table III adds a variable for whether or not the individual has employer-provided health insurance. The estimated coefficient is highly significant and implies that workers in jobs with health insurance have a 60 percent lower likelihood of turnover than equivalent workers in jobs without health insurance. Note that when health insurance is included as a regressor, the impact of wages falls substantially, by about one half. ${ }^{14}$ Moreover, the coefficient on health insurance is substantially larger than that on wages. This suggests that increasing employer spending on health insurance has a greater effect on turnover than an equivalent increase in wages. ${ }^{15}$ As mentioned previously, however, the

14 Although this reduction of the wage coefficient may seem large, Mitchell (1982) finds a similar result for pensions. In her study, including a dummy variable for whether or not an individual has a pension reduces the wage coefficient by 40 percent.

${ }^{15}$ A recent poll asked how much extra wage income individuals would have to receive in order to give up their employer-provided health insurance [Employee Benefit Research Institute, 1991]. The mean response was $\$ 4,850$ (in contrast, the average cost of providing health insurance was $\$ 2,748$ per employee in 1989.) If employees value health insurance just as they value wages, then the effect of health insurance should be similar to the effect of increasing income by $\$ 5,000$ per year. 
effect of health insurance alone cannot be construed as evidence of joblock because jobs which provide health insurance typically provide many other benefits as well.

\section{A. Cost Factor 1: Having Other Health Insurance}

To examine the effect of job-lock, the third column of Table III includes Other $\mathrm{HI}$ and its interaction with Health Insurance as regressors. The two tests for job-lock outlined previously are presented in the bottom panel of Table III (because both hypotheses concerning job-lock are onesided, the reported p-values correspond to a one-tailed test). The first is whether among those with employer-provided health insurance, those who have other health insurance should be more likely to change jobs than those who do not have alternative coverage. The statistic for this test, $\hat{\beta}_{2}+\hat{\beta}_{3}$, is positive $(.171)$ with a $\mathrm{p}$-value of .017 . The second test statistic, for whether having other health insurance increases mobility more among those with employer-provided health insurance than among those without it, is simply $\hat{\beta}_{3}$ (the coefficient on the interaction between employerprovided health insurance and other health insurance). It is also positive (.211) with a $\mathrm{p}$-value of .058 . Both of these test give strong evidence of insurance-related job-lock.

The actual effect of job-lock may be more easily seen, however, by once again considering a mobility matrix, this time with the estimated probability of changing jobs over a 12 month period in each cell (standard

Because most income is wage income, we would therefore expect the coefficient on health insurance to be smaller than that on wages if employees value wages and health insurance equally. 
errors are in parentheses). ${ }^{16}$ The turnover probability is calculated for a representative individual: a white, 38-year old man with 13 years of schooling and 19 years of experience who works in a non-union manufacturing job as a craftsman, earns an hourly wage $\$ 11.50$, and has a total family income of $\$ 36,000 .{ }^{17}$

The predicted probability of turnover for an individual with no health insurance is .256 . Similarly, the turnover probability for an individual with employer-provided insurance but no other source of coverage is .085 (as expected, mobility is much lower for those with employer-provided health insurance than for those without). $\quad \mathrm{T} \mathrm{h} \mathrm{e}$ striking feature of this matrix is that while individuals with other health insurance only are slightly less (5.1 percent) likely to change jobs than individuals with no health insurance, individuals with both sources of health insurance are much more (26.0 percent) likely to change jobs than those who only have employer-provided health insurance.

${ }^{16}$ The variance for the predicted probabilities, $\hat{P}=P\left(\mathbf{x}^{\prime} \hat{\beta}\right)$, is computed as

$$
\operatorname{Var}[\hat{P}]=\left(\frac{\delta \hat{P}}{\delta \hat{\beta}}\right)^{\prime} \operatorname{Var}[\hat{\beta}]\left(\frac{\delta \hat{P}}{\delta \hat{\beta}}\right)
$$

17 These characteristics correspond roughly to the averages in the sample (or the mode for categorical variables). The average probabilities for everyone in the sample look very similar to those computed for the representative individual, and the corresponding estimates of job-lock are likewise very similar. 
Employer-Provided Health Insurance

Predicted Turnover

Probabilities

No Yes

\begin{tabular}{lllll}
\hline No Other HI & .256 & $(.032)$ & .085 & $(.012)$ \\
Other HI & .244 & $(.032)$ & .115 & $(.017)$ \\
\hline $\begin{array}{l}\text { Estimates of Job-Lock } \\
\begin{array}{l}\text { a. Row difference among } \\
\text { those with HI }\end{array}\end{array}$ \\
$\begin{array}{l}\text { b. Simple difference-in- } \\
\text { difference }\end{array}$ \\
$\begin{array}{l}\text { c. Adjusted difference-in- } \\
\text { difference }\end{array}$ & $31.1 \%$ & $(17.7)$ \\
\hline \hline
\end{tabular}

Three estimates of job-lock are presented below the matrix. The first estimate gives the increased mobility of those with both sources of health insurance over those with only employer-provided health insurance (column 2) and suggests that job-lock is responsible for a 26 percent reduction in mobility (this calculation uses those with other health insurance, who should not affected by job-lock, as the base group). The next two estimates of job-lock attempt to account for any independent effect of other health insurance on mobility. A simple difference-indifference estimate, the row difference in the second column minus that in the first column, gives an estimate for job-lock of 31.1 percent (26.0-(5.1)). An alternative (adjusted) difference-in-difference estimate can be obtained by comparing the actual mobility rate of those with both sources of health insurance to the counterfactual mobility rate of this group if the effect of other health insurance were the same as for those without employer-provided health insurance. The row difference in column 1 
suggests that other health insurance reduces mobility by 5.1 percent among those who do not have employer-provided health insurance; if the effect is similar for those who do have employer-provided health insurance, then the mobility rate of those with both sources of health insurance would be .081 rather than $.115 .^{18}$ The magnitude of job-lock is then a 29.6 percent $((.115-.081) / .115)$ reduction in mobility among those with employer-provided health insurance. Because other health insurance alone does not have a substantial impact on mobility (as suggested by the small row difference in column 1), the measure of job-lock computed from the simple row difference among those with employer-provided health insurance and both difference-in-difference estimates are quite similar. ${ }^{19}$ The last row of Table III gives the range of these estimates as the degree of job-lock.

The last column in Table III gives the results from estimating a random effects probit model for turnover (obtained by maximizing the likelihood function specified in equations 6 and 7). Note that the coefficients in columns 3 and 4 are not directly comparable because those for the simple probit give the effect on between-interview turnover while

${ }^{18}$ The number .081 is derived by dividing .085 (the mobility rate of those with only employment-based insurance) by 1.051 because the mobility rate of those with only other health insurance is $5.1 \%$ lower than that of individuals with no health insurance.

${ }_{19}$ Given the similarity between the two difference-in-difference estimates of job-lock, some may question the need for an adjusted estimate. The adjusted estimate is actually preferable because it is possible for the simple estimate to exceed $100 \%$, and a reduction in mobility greater than $100 \%$ does not make sense. The two estimates are similar here because the row difference in column 1 is so small. It will matter, however, when we come to the pregnancy "experiment". 
those for the random effects probit correspond to monthly turnover. The relative magnitudes, however, are very similar (i.e, the coefficient on health insurance is roughly twice that on wages in both specifications), as are the predicted probabilities of job change over a 12-month interval. While the standard errors are slightly larger using the random effects specification, the qualitative results are very similar: job-lock accounts for a 25-30 percent reduction in mobility.

Because the predominant source of other health insurance comes from a spouse's employment, it is possible that the effect of other health insurance is in reality the effect of having a working wife. ${ }^{20}$ Certainly having a second source of income in the family would make it easier for an individual to give up his current job if he had not yet lined up another. To control for this, I have also included family income and wife's income as regressors. Although the results are not reported, the coefficient estimates on $\beta_{2}$ and $\beta_{3}$ are virtually unchanged when these income measures are included, and the estimates of job-lock are likewise very similar. These results suggest that the increased mobility for men whose wives also have health insurance does not merely capture the impact of having a working spouse. This conclusion is further supported when the estimation is confined solely to those men whose wive's are working. In this case both tests of job-lock are actually more significant than those for the full sample despite a 40 percent reduction in sample size, and the estimated magnitude of job-lock is larger ( 36 percent to 51 percent). Once

${ }^{20}$ To the extent that having a working spouse precludes making job changes that also entail moving geographically, these estimates of job-lock may actually be understated. 
again, controlling for family income, wife's income or wife's wages do not alter the results substantially.

\section{B. Cost Factor 2: Expected Medical Expenses and Family Size}

Table III moves to the second job-lock experiment in which family size is used as a proxy for expected medical expenses. The actual equation estimated is the same as before except that $\beta_{2}$ now corresponds to family size (rather than other health insurance) and $\beta_{3}$ to the interaction between having employer-provided health insurance that covers others and family size. As before, we can consider two tests of job-lock: whether having health insurance that covers others reduces mobility more for individuals with large families $\left(\beta_{2}+\beta_{3}<0\right)$, and whether the differential mobility between small and large families is greater for those with employer-provided health insurance than for those without it. $\left(\beta_{3}<0\right){ }^{21}$

As mentioned in the description of the data, I use both a conservative and a liberal measure of whether the husband's health insurance covers others in the family (column 1 and column 2 of Table IV). In both cases, the tests for $\beta_{2}+\beta_{3}$ and for $\beta_{3}$ alone suggest evidence of job-lock. Although the effects are much more significant for the conservative test, the actual estimates are almost identical. Using the conservative measure of covering others gives a stronger test of job-lock because when using the liberal measure, the effect of covering others will be partially offset by the fact that having a wife with employer-provided

${ }^{21}$ The predicted signs are opposite those in the other health insurance case because having other health insurance should increase mobility for those with employer-provided health insurance while having a large family should decrease mobility. 
health insurance reduces job-lock. The third column of Table IV looks only at families for whom the wife does not have employer-provided health insurance and, as could be expected, the results on job-lock in column 3 are stronger and of a greater magnitude than those in column 2 . In all three cases, family size has a negative impact on mobility, but this effect is insignificant. The last column in Table IV gives the results from estimating a random effects probit using the full sample and the conservative estimate of covering others. As was the case with other health insurance, the results from estimating a random effects probit looking at family size (presented in the last column of Table 4) are qualitatively similar to those of the simple probit.

\begin{tabular}{lcccc}
\hline \hline & \multicolumn{2}{c}{ Employer-Provided Health Insurance } \\
\cline { 2 - 5 } $\begin{array}{l}\text { Predicted Turnover } \\
\text { Probabilities }\end{array}$ & \multicolumn{2}{c}{ No } & \multicolumn{2}{c}{ Yes } \\
\hline 1 Child & .253 & $(.027)$ & .092 & $(.012)$ \\
5 Children & .224 & $(.041)$ & .051 & $(.014)$ \\
\hline
\end{tabular}

Estimates of Job-Lock
a. Row difference among those with HI
b. Simple difference-in- difference
c. Adjusted difference-in- difference
$44.5 \%$
$33.0 \%$
$37.3 \%$

The magnitude of job-lock can once again be derived from the predicted probabilities in a mobility matrix. In this case, the estimates come from the results in column 1 of Table 4 with the probabilities in the 
first row corresponding to an individual with one child, while those in the second row correspond to an individual with 5 children. Although family size decreases the probability of changing jobs regardless of health insurance status, the negative effect of family size on turnover is much larger for those with employer-provided health insurance. Not only is the relative reduction in mobility larger ( 44.5 percent versus 11.6 percent), but the absolute reduction in mobility is larger as well (.041 versus .029).

Looking only at the difference in mobility rates of large and small families among those with health insurance, the estimated effect of joblock is a 44.5 percent reduction in mobility among those with employerprovided health insurance. Accounting for the negative (albeit insignificant) effect of family size using a simple difference-in-difference estimate gives a more conservative measure of job-lock ( 33 percent), while the adjusted difference-in-difference estimate effect of job-lock from having four additional children would be to reduce mobility by 37 percent. These estimates of job-lock obviously depend on the arbitrarily chosen family size for the small and large family. Comparing a family of 2 children with a family of 4 children gives a difference-in-difference estimate of job-lock of about 25 percent.

\section{Cost Factor 3: Expected Medical Expenses and Pregnancy}

Results using pregnancy as a preexisting condition are presented in Table 5. The first two columns use the percent of time pregnant as the measure of pregnancy, while the last two columns use a dummy variable for whether or not the individual had a baby. In the estimated equation, $\beta_{2}$ now corresponds to pregnancy while $\beta_{3}$ corresponds to the interaction between pregnancy and employer-provided health insurance. The two tests 
for job-lock are whether pregnancy reduces mobility among those who have health insurance $\left(\beta_{2}+\beta_{3}<0\right)$ and whether health insurance reduces mobility more for those who are expecting a child than for those who are not expecting $\left(\beta_{3}<0\right)$.

As columns 1 and 3 of Table 5 show, both measures of pregnancy suggest evidence of job-lock and, as expected, using the fraction of time pregnant does give stronger results. Looking only at the individuals most likely to have children, those aged 20-39, does not alter the results significantly (columns 2 and 4). The last column of Table 5 presents the results from estimating a random effects probit corresponding to the simple probit in column 1. As before, the results from the random effects probit and the simple probit are qualitatively similar.

The tests of job-lock in the pregnancy experiment are less compelling than those from the other health insurance and family size experiments. While the test of $\beta_{3}<0$ is significant, the simple test of $\beta_{2}+\beta_{3}<0$ is only significant at the 70 percent to 80 percent level. The significance of the difference-in-difference estimator $\beta_{3}$ is due largely to the fact that among individuals who do not have employer-provided health insurance, pregnancy actually increases mobility $\left(\beta_{2}>0\right)$. This result may seem counterintuitive, however, it should not seem too surprising that these individuals may be motivated to find better jobs precisely because they are expecting a child. Since not all firms exclude preexisting conditions, there is a chance that an individual in a job which does not currently provide health insurance will find a new job which provides health insurance that will pay for the delivery.

Even though the test $\beta_{2}+\beta_{3}$ is not as significant as that from the other health insurance and family size experiments, its magnitude is still 
large enough that it gives evidence of job-lock within the range of the previous two experiments. This is shown in the mobility matrix below based on column 1 of Table 5. Note that among those who do not have employer-provided health insurance, the predicted mobility rate of individuals who are expecting a child is more than twice that of individuals who are not expecting (the row difference in column 1). In contrast, among those who do have employer-provided health insurance, individuals who are expecting have a predicted mobility rate 31 percent lower than those who are not expecting. The effect of job-lock using the row difference in column 2 is therefore 31 percent.

\begin{tabular}{|c|c|c|c|c|}
\hline \multirow{3}{*}{$\begin{array}{l}\text { Predicted Turnover } \\
\text { Probabilities } \\
\text { Wife not pregnant }\end{array}$} & \multicolumn{4}{|c|}{ Employer-Provided Health Insurance } \\
\hline & \multicolumn{2}{|c|}{ No } & \multicolumn{2}{|c|}{ Yes } \\
\hline & .242 & $(.026)$ & .097 & $(.012)$ \\
\hline Wife pregnant & .502 & $(.147)$ & .067 & $(.040)$ \\
\hline \multicolumn{5}{|l|}{ Estimates of Job-Lock } \\
\hline $\begin{array}{l}\text { a. Row difference among } \\
\text { those with } \mathrm{HI}\end{array}$ & & $30.9 \%$ & $(37.8)$ & \\
\hline $\begin{array}{l}\text { b. Simple difference-in- } \\
\text { difference }\end{array}$ & & $138.7 \%$ & $(51.8)$ & \\
\hline $\begin{array}{l}\text { c. Adjusted difference-in- } \\
\text { difference }\end{array}$ & & $66.7 \%$ & $(20.7)$ & \\
\hline
\end{tabular}

The simple difference-in-difference estimate of the effect of joblock is 139 percent, while the adjusted difference-in-difference estimate of job-lock is 67 percent. In this case, the adjusted difference-in-difference estimate makes much more sense than the simple difference-in-difference 
estimate because a reduction in mobility rates greater than 100 percent is impossible. Evenso, because the effect of pregnancy on mobility is positive for those without group employment health insurance and negative for those with such insurance, the rationale for using either difference-indifference measure of job-lock is less compelling than when looking at family size for evidence of job-lock. ${ }^{22}$. The last row of Table 5 gives the row difference and the adjusted difference-in-difference measures of joblock for the other specifications which look at pregnancy.

Some may question whether a more accurate portrayal of the link between pregnancy and job mobility is one in which individuals find the "good" job which offers health insurance and then decide to have children. To the extent that this type of behavior occurs, it should lead to an underestimate of the magnitude of job-lock because it suggests that among those with health insurance, those who are expecting a child will have lower job tenure than those who are not, and the previous literature on job-mobility has consistently found a negative relationship between tenure and job turnover. ${ }^{23}$

${ }^{22}$ This is particularly true if part of the mobility differential among those without insurance between those who are expecting and those who are not is motivated by the former group trying to find jobs with health insurance (this would be a kind of reverse job-lock).

${ }^{23}$ Calculations by the author using data from the May 1988 Current Population Survey show that the fraction of men with a child under the age of one is roughly equal for all tenure levels between one and five years, even after controlling for age. This suggests that most children are not conceived in response to their parents having found a good job and the bias created by this type of behavior is therefore not likely to be significant. 
I attempted to confirm my results of pregnancy-related job-lock by estimating a hazard model of voluntary mobility using data from the National Longitudinal Survey of Youth (NLSY). This dataset has the advantage of precisely dating (month, day and year) both job changes and births. The measured effect of job-lock using the NLSY was the "wrong" sign, although the standard error on the interaction between pregnancy and employer-provided health insurance was so large that it precluded making any inferences. An attempt to reconcile the differing results from these two datasets was not particularly fruitful, although there is some suggestion that the lack of evidence for job-lock in the NLSY is due partly to the fact that most of the births were first births.

Following the framework in Section II, Holtz-Eakin [1993] also examines the issue of job-lock. In contrast to the results presented above, his analysis using data from the Panel Study of Income Dynamics (PSID) gives little evidence of job-lock. These differences may be attributable to disparities in data quality between the NMES and the PSID. The PSID is known to have noisy and often inconsistent measures of job turnover which result from questions on job tenure that are somewhat ambiguous. Brown and Light [1992] show that the coefficients from probit estimation using PSID turnover measures as the dependent variable are quite sensitive, both in sign and magnitude, to how one cleans the data. In contrast, the NMES data on turnover is derived from questions asked each quarter about an individual's actual place of employment. Aggregate measures of turnover in the NMES are quite similar to those derived from the CPS and the SIPP for a similar time period. 


\section{Specification Checks}

There is one variable which should perhaps be included in all of the mobility equations that is missing, and that is tenure. Unfortunately, the NMES did not survey participants about their job duration. If having health insurance is correlated with tenure, the coefficients which I use to identify job-lock could be biased by the omission of tenure. Applying the standard formula for omitted variables in a probit [Yatchew and Griliches, 1985], I estimate that the omission of tenure biases the coefficient on health insurance and the other coefficients related to job-lock by at most 30 percent. Correcting for these biases does not change the conclusion that there is substantial insurance-related job-lock.

The estimates of job-lock found in all three experiments are robust to general changes in specification. Estimating a logit or a linear probability model of turnover rather than a probit does not change things substantively. Using education dummies rather than a linear education variable does not change the estimates of job-lock. Likewise, adding an experience-squared term or weighting the data do not change the estimates of job-lock.

Table 6 compares the estimated impact of job-lock from the three different experiments. As noted previously, we should expect to see more evidence of job-lock among individuals with higher expected medical expenses. Columns 3 and 4 give the estimated impact of job-lock, while column 5 lists the expected family medical expenses for the group specified in each experiment. While there appears to be little relationship between the effect of job-lock based on $\hat{\beta}_{2}+\hat{\beta}_{3}$ and expected medical expenses, the effect using $\hat{\beta}_{3}$ and expected medical expenses are highly correlated. For example, the effect of job-lock based on $\hat{\beta}_{3}$ from the other 
health insurance experiment is 66 percent that from the family size experiment, and expected medical expenses for other health insurance are 80 percent those of family size. Similarly, the effect of job-lock from the family size experiment is 51 percent the effect of using $\hat{\beta}_{3}$ from the pregnancy experiment, while expected medical costs are 54 percent of those for an expectant family. This suggests that the difference in the mobility rates of the control and the experimental group between those with health insurance and those without health insurance is largely accounted for by differences in expected medical costs faced by these groups.

\section{Conclusions}

The evidence presented above suggests that there is substantial health insurance-related job-lock. The change in mobility from having other health insurance is 25 percent greater for those with employerprovided health insurance than for those without employer-provided health insurance. In addition, individuals with larger families are less likely to leave their jobs if they have health insurance than if they do not. And finally, while having a wife who is pregnant increases mobility among those with no health insurance, it reduces mobility substantially (30 percent to 40 percent) for those who have employer-provided health insurance. These results are robust to changes in specification and in the sample over which they are estimated.

Estimating the welfare consequences associated with job-lock is a more difficult issue. Although an explicit welfare calculation is beyond the scope of this paper, there are three factors to consider in evaluating the implications of job-lock for economic efficiency. The first is whether 
there is an important match specific component to individual productivity. If job turnover results in increased match quality between workers and firms, job-lock will result in a loss of economic efficiency. In contrast, if workers are essentially "replaceable", job-lock will only affect the distribution of output. To the extent that job-lock does lower productivity, a second important consideration is whether these losses are temporary or permanent. While pregnancy is a preexisting condition that comes and goes in a matter of months, some of individuals facing job-lock will be affected by conditions that last for years.

Finally, some might ask whether job-lock is a benefit, rather than a cost, for firms. If firms make job-specific investments in worker human capital, they may want to reduce turnover among their employees. This is a commonly cited reason for employer provision of pensions. The effect of job-lock, however, is separate from the general mobility reducing effect that results from the provision of fringe benefits because it is the workers with high expected medical expenses who will be most likely to stay. Presumably the firm would rather reduce turnover among workers with low expected medical expenses than among those with high expected medical expenses. More importantly, job-lock is not created by the firm but is imposed by the benefit policies of other firms, either because other firms exclude preexisting conditions or, less frequently, because they do not offer health insurance. 


\section{REFERENCES}

Agency for Health Care Policy and Research, 1987 National Medical Expenditure Survey: Public Use Tape 13 Household Survey Population Characteristics and Utilization Data for 1987, (Rockville, MD: AHCPR, 1991).

Bartel, Ann, "Wages, Nonwage Job Characteristics and Labor Mobility," Industrial and Labor Relations Review, XXXV (1982), 578-589.

Bartel, Ann and George Borjas, "Middle-Age Job Mobility: Its Determinants and Consequences," in Seymour Wolfbein, ed., Men in the Pre-Retirement Years, (Philadelphia: Temple University Press, 1977).

Brown, James and Audrey Light, "Interpreting Panel Data on Job Tenure," Journal of Labor Economics, X (1992), 219-257.

Cotton, Paul, "Preexisting Conditions 'Hold Americans Hostage' to Employers and Insurance," Journal of the American Medical Association, CCLXV (1991), 2451-2453.

Employee Benefits Research Institute, Public Attitudes on Benefit Trade Offs, (Washington, DC: Employee Benefit Research Institute, 1991).

Gruber, Jonathan and Brigitte C. Madrian, "Limited Insurance Portability and Job Mobility: The Effects of Public Policy on Job-Lock," unpublished manuscript, Massachusetts Institute of Technology, 1993.

Gustman, Alan and Thomas Steinmeier, "Pension Portability and Labor Mobility: Evidence from the Survey of Income and Program Participation," NBER Working Paper No. 3525, (Cambridge, MA: National Bureau of Economic Research, 1990).

Gustman, Alan and Thomas Steinmeier, "Pensions, Efficiency Wages, and Job Mobility, "NBER Working Paper No. 2426, (Cambridge MA: National Bureau of Economic Research, 1987). 
Health Insurance Association of American, The Cost of Maternity Care and Childbirth in the United States, Research Bulletin R1589, (Washington, DC: HIAA, 1989).

Holtz-Eakin, Douglas, "Health Insurance Provision and Labor Market Efficiency in the United States and Germany," NBER Working Paper No. 4388, (Cambridge, MA: National Bureau of Economic Research, 1993).

Jovanovic, Boyan, "Job Matching and the Theory of Turnover," Journal of Political Economy, LXXXVII (1979), 972-990.

Manning, Willard G., et al, Health Insurance and the Demand for Medical Care: Evidence from a Randomized Experiment, R-3476HHS, (Santa Monica, CA: The RAND Corporation, 1988).

McCormick, Barry and Gordon Hughes, "The Influence of Pensions on Job Mobility, "Journal of Public Economics, XXIII (1984), 183206.

Mitchell, Olivia, "Fringe Benefits and the Cost of Changing Jobs," Industrial and Labor Relations Review, XXXCII (1983), 70-80.

Mitchell, Olivia, "Fringe Benefits and Labor Mobility," Journal of Human Resources, XVII (1982), 286-298.

Mortensen, Dale T., "Job Search and Labor Market Analysis," in O. Ashenfelter and R. Layard, eds., Handbook of Labor Economics, Volume II, (Amsterdam: North-Holland, 1986).

New York Times, "Health Benefits Found to Deter Job Switching," September 6, 1 .

Piacentini, Joseph S. and Michael A. Anzick, "Employee Benefits in Total Compensation," EBRI Issue Brief No. 111, (Washington, DC: Employee Benefit Research Institute, 1991).

Schiller, Bradley R. and Randall D. Weiss, "The Impact of Private Pensions on Firm Attachment," Review of Economics and Statistics, LXV (1979), 369-80. 
Spencer Associates, Spencer's Research Reports on Employee Benefits, 329.04.-1, (Chicago, IL: Charles D. Spencer \& Associates, July $5,1991)$.

U. S. Department of Labor, Bureau of Labor Statistics, Employee Benefits in Medium and Large Firms, (Washington DC: Government Printing Office, 1989).

Yatchew, A. and Zvi Griliches, "Specification Error in Probit Models," Review of Economics and Statistics, LXVI (1985), 134-139. 


\section{TABLE I}

Sources of Health Insurance Coverage

\begin{tabular}{lcc}
\hline \hline & $\begin{array}{c}\text { Fraction who have } \\
\text { coverage through: }\end{array}$ & $\begin{array}{c}\text { Fraction with } \\
\text { employer coverage } \\
\text { who also have: }\end{array}$ \\
\hline Own employment & $75.0 \%$ & $100 \%$ \\
Spouse's employment & 33.5 & 36.0 \\
Union & 4.5 & 0.5 \\
Other group policy & 0.4 & 0.3 \\
Non-group policy & 2.3 & 0.6 \\
CHAMPUS & 2.1 & 1.7 \\
Medicaid & 0.5 & 0.0 \\
Any non-employer source & 41.0 & 37.5 \\
\hline \hline
\end{tabular}

Author's calculation using a sample of 2978 married men from the 1987 National Medcial Expenditure Survey. 
Descriptive Statistics

(1987 National Medical Expenditure Survey)

\begin{tabular}{|c|c|c|c|c|}
\hline Variable & Mean & $\begin{array}{c}\text { Standard } \\
\text { Error }\end{array}$ & Minimum & Maximum \\
\hline Union & 0.25 & 0.432 & 0 & 1 \\
\hline Black & 0.15 & 0.359 & 0 & 1 \\
\hline Education & 12.88 & 2.930 & 0 & 18 \\
\hline Experience & 19.18 & 9.110 & 0 & 47 \\
\hline Hourly wage & $\$ 11.53$ & $\$ 7.23$ & $\$ 1.06$ & $\$ 192.31$ \\
\hline Log hourly wage & 2.30 & 0.554 & 0.06 & 5.26 \\
\hline Log family income & 10.51 & 0.808 & 0 & 12.99 \\
\hline Log wife's income & 7.72 & 0.332 & 0 & 12.52 \\
\hline Health Insurance & 0.75 & 0.432 & 0 & 1 \\
\hline Other Health Insurance & 0.41 & 0.491 & 0 & 1 \\
\hline Family Size & 3.36 & 0.121 & 2 & 12 \\
\hline Pregnant & 0.06 & 0.246 & 0 & 1 \\
\hline
\end{tabular}

Author's calculation using a sample of 2978 married men from the 1987 National Medical Expenditure Survey. 


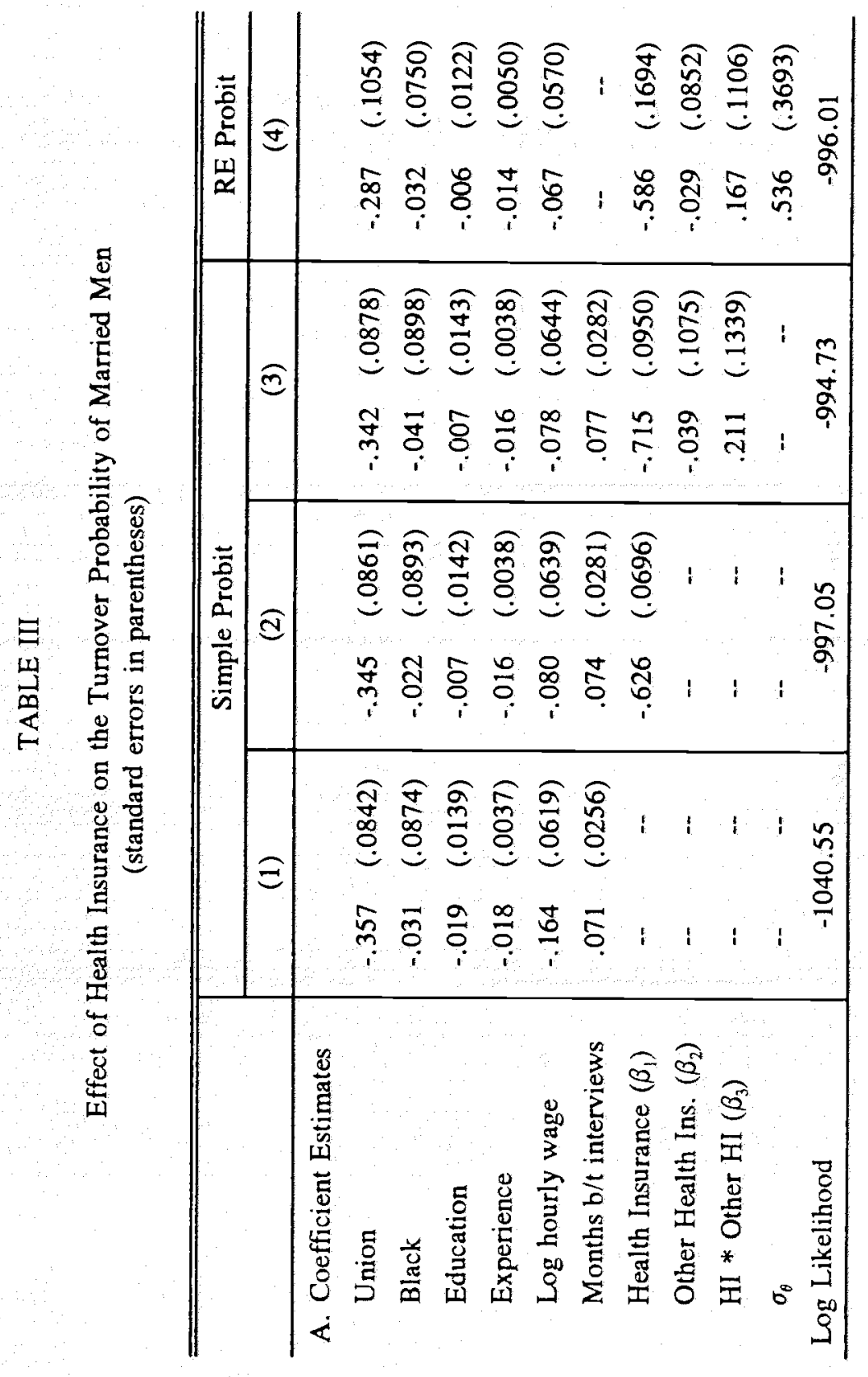




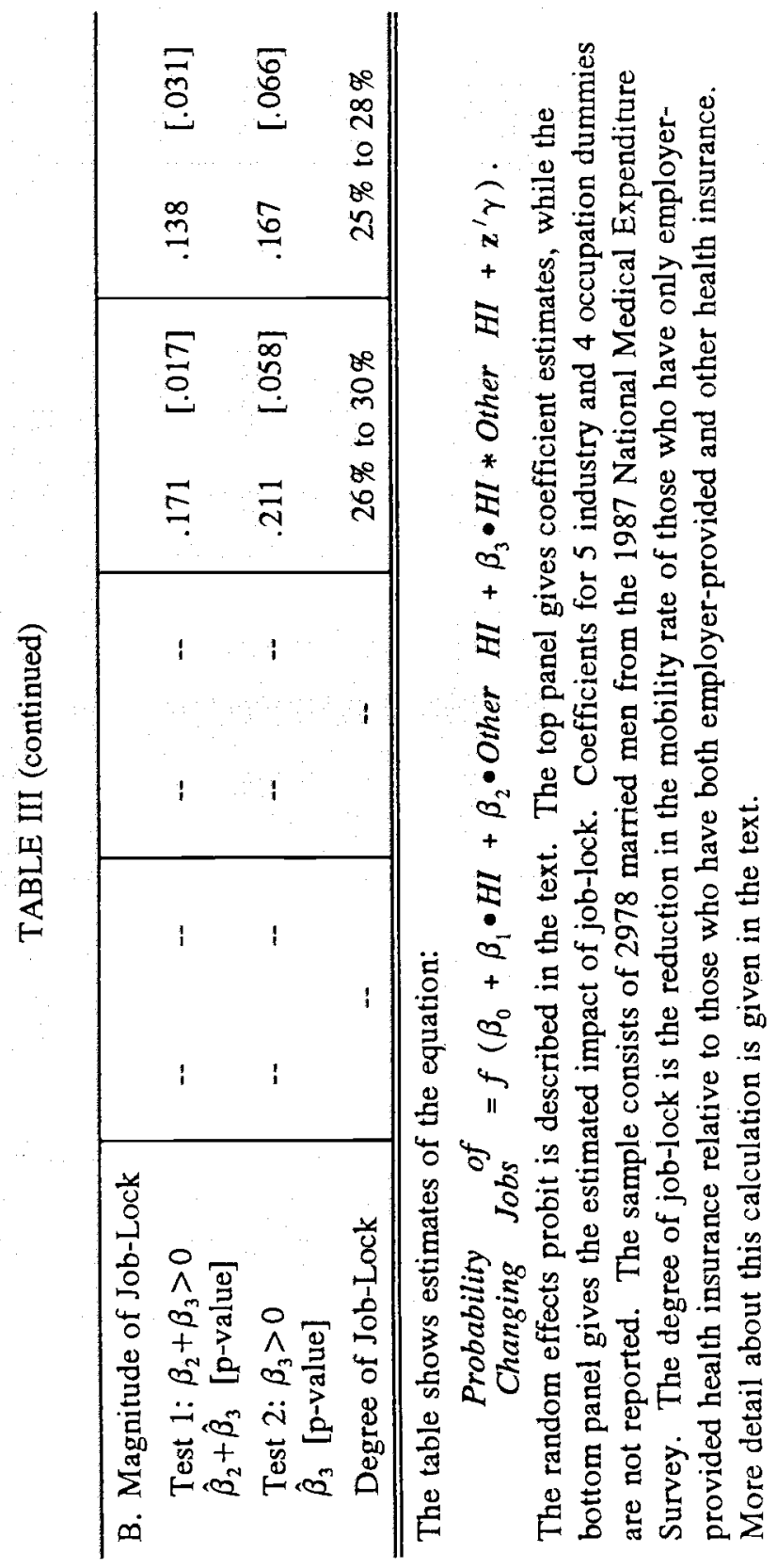




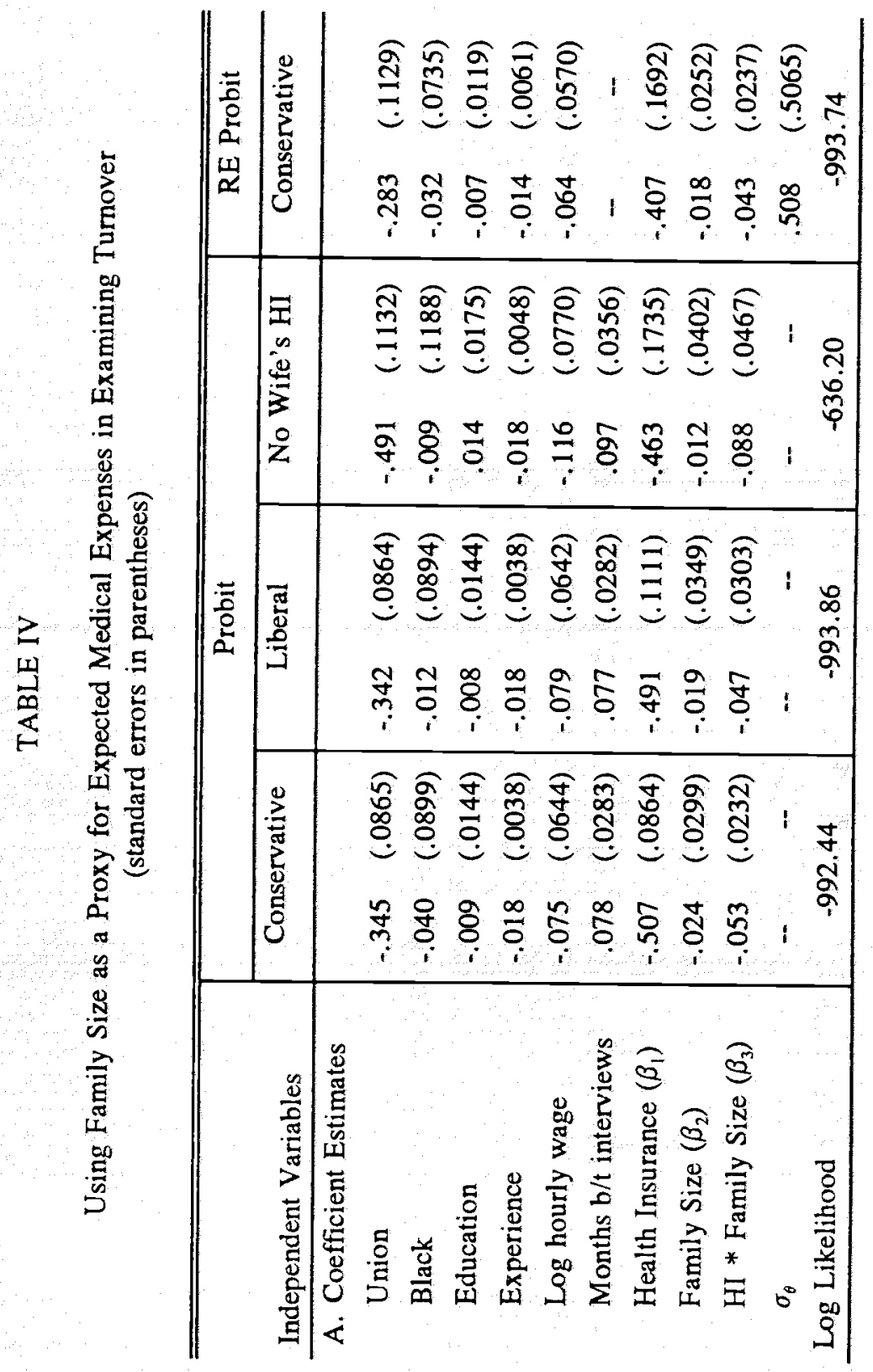




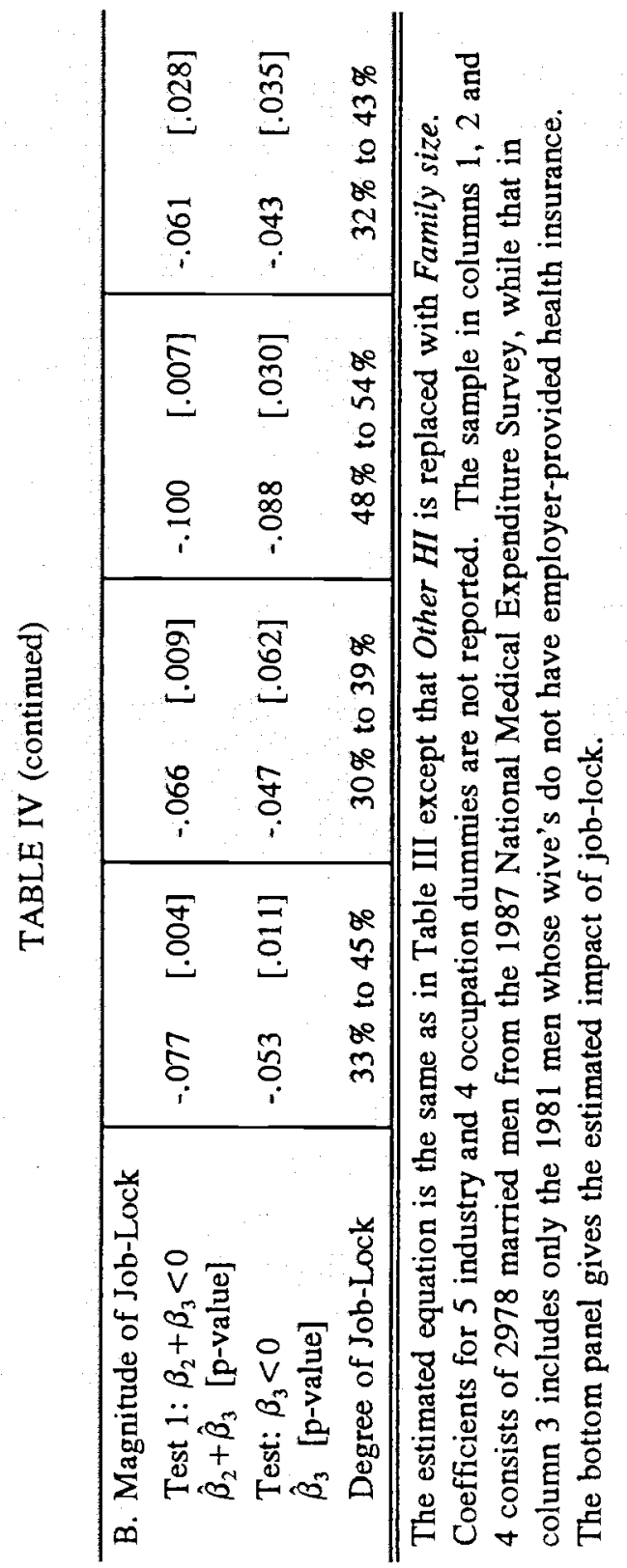




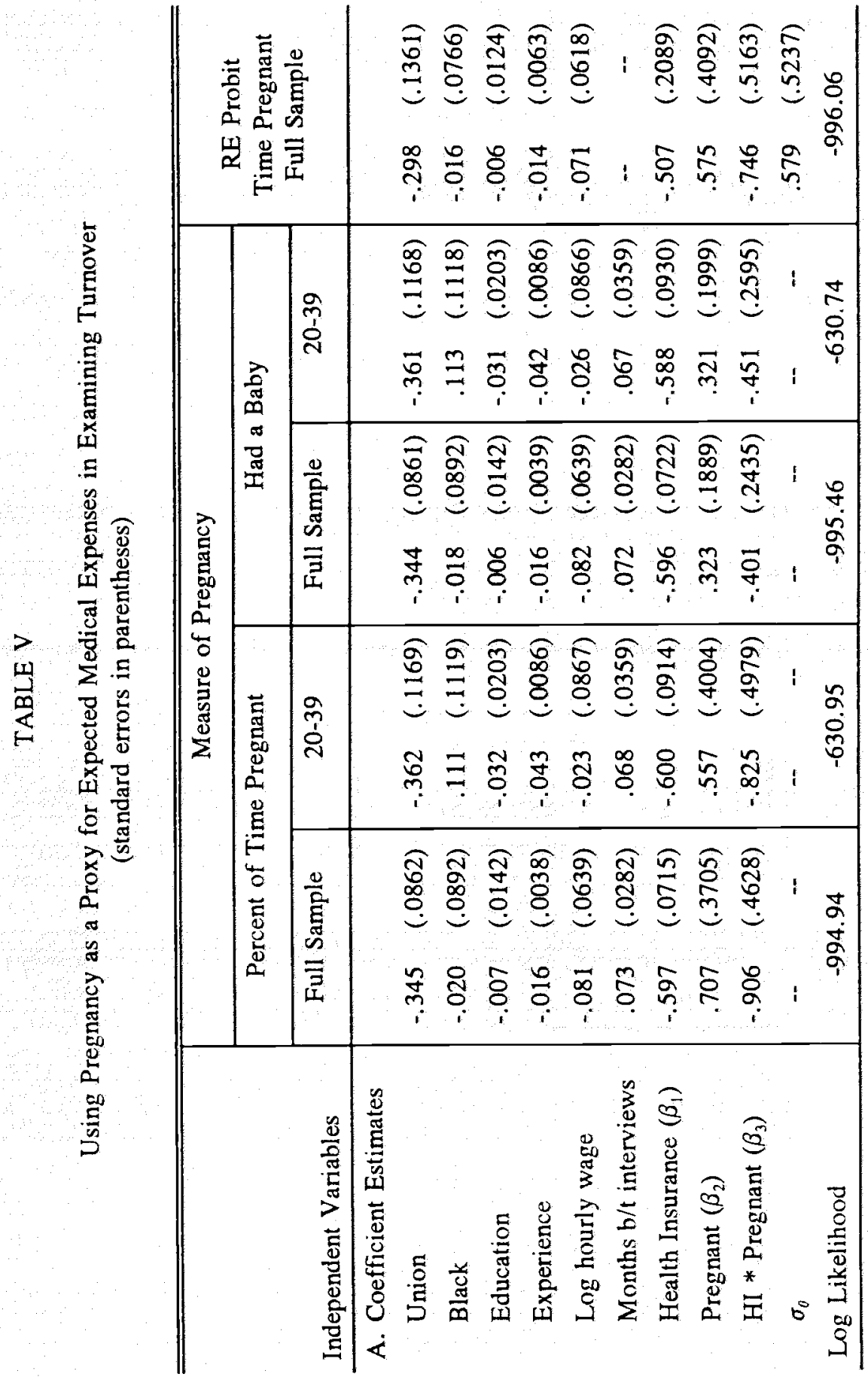




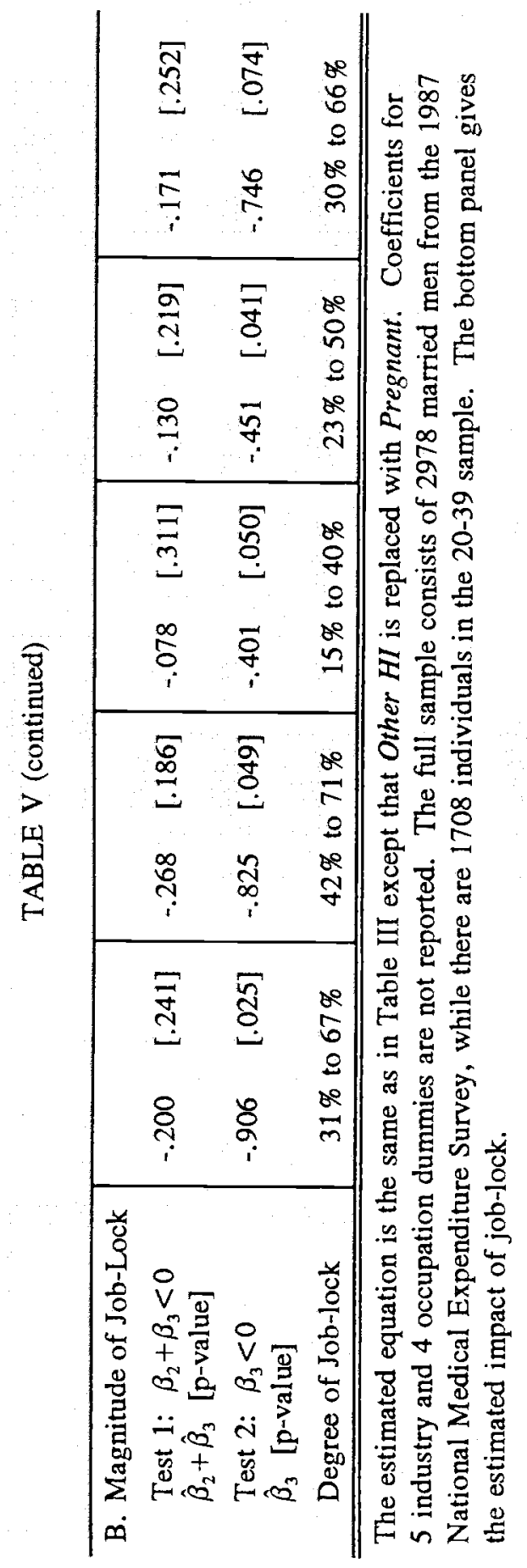


Calibrating the Magnitude of Job-Lock

\begin{tabular}{llccc}
\hline \hline Experiment & Family & $\begin{array}{c}\text { Estimated } \\
\text { Effect }^{2}\end{array}$ & $\begin{array}{c}\text { Expected } \\
\text { Medical }\end{array}$ \\
\cline { 2 - 5 } & & $\beta_{2}+\beta_{3}$ & $\beta_{3}$ & $\begin{array}{c}\text { Expenses } \\
(1984 \$)^{\mathrm{b}}\end{array}$ \\
\hline Other HI & 2 children & .171 & .211 & $\$ 2318$ \\
Family Size & 4 children & .462 & .318 & $\$ 2892$ \\
Pregnancy & 1 child & .201 & .619 & $\$ 5371$ \\
& expecting another & & & \\
\hline \hline
\end{tabular}

- The estimated effect of job-lock for other health insurance is taken from column 3 of Table 5 . For family size, the coefficients from column 1 of Table 9 are multiplied by 6 , the family size of the base group. In the case of pregnancy, the coefficients from column 2 of Table 10 are multiplied by .75 (the fraction of a year for which an expectant mother is pregnant).

b For other health insurance and family size, expected medical expenses of $\$ 287$ for children and $\$ 872$ for adults are taken from Table 5 of Manning et al. (1987). For pregnancy, expected medical expense is calculated as the cost of 1 child and 2 adults from Manning et al. plus the average cost of pregnancy and delivery of $\$ 3340$ (Health Insurance Association of America 1989; deflated by the medical care CPI between 1984 and 1988). 